\title{
Turning to the Pedagogy of "Listening"
}

\author{
ZHANG HUA \\ Hangzhou Normal University (China)
}

\begin{abstract}
"Lecturing" pedagogy puts teachers' lecturing at the core of education. Both knowledge and norms become the "goods" waiting to be transmitted to students. This pedagogy keeps a controlbased axiology and mirror-based epistemology. The "listening" pedagogy puts teachers' listening and mutual listening between teachers and students, among students as the core of education. On the level of axiology, it makes "good listeners" i.e. persons with freedom as the aim of education, who integrate morality and creativity. On the level of epistemology, it sees educational process as the cooperative creation of knowledge. On the level of methodology, it integrates listening, description, interpretation, and action as a whole. In today's China, educational fields should turn to the paradigm of a "listening" pedagogy.
\end{abstract}

Contemporary pedagogy in China is essentially a pedagogy of "lecturing" based on the transmission and reception of human's existing knowledge and norms and centralized around teachers' lecturing. Since the end of the 19th century and early 20th century, however, a new pedagogy corresponding to the time of democracy turned up as the pedagogy of "listening" that characterizes the creation of knowledge, the reflection and transcendence of existing customs and the cultivation of individual's competencies of action and reflective practice, that sees teachers' listening and mutual listening among students and between teachers and students as its "main melody". Now it is the time for Chinese educators to construct their own pedagogy of listening in answer to the requirement of the new era.

\section{The origin and essence of "lecturing" pedagogy}

In the West, the tradition of "lecturing" pedagogy dates back to the sophists in ancient Greece. The sophists were the first specialized educators in the history of western education, a group of people who "lived by their tongues", even "used their tongues to collect fruits", and "only believed in the sky, clouds and tongues rather than God" (Aristophanes, 1954). They were "elocutionists" and highlighted the development of "elocutionists" as their teaching objective, which was in the final sense to participate in politics and seize power. As Hegel wrote:

The object of the Sophists has thus been to teach what the mainspring of the world is, and since philosophy alone knows that this is the universal thought which resolves all that is particular, the Sophists were also speculative philosophers (Hegel, 1983). 
To train people as "elocutionists" with political power, the sophists employed speech and debate as primary methods to teach sophistic, rhetoric and grammar, added by arithmetic, geometry, astronomy, music and so forth.

The sophists were apparently the earliest advocators and implementers of "lecturing" pedagogy in the history of western education, whose main contribution has been to create the tradition of "lecturing" in the West and to introduce logical inquiry into the educational arena. The "seven liberal arts" they preached were the first academic courses in the West. However, even in ancient Greek time, "the sophist school" went downhill soon, and the sophists, were gradually debased and criticized as "hairsplitting wordsmiths" who confused truth and falsehood and disregarded moral principles in pursuit of profits. The fundamental reason behind this is that the sophists eventually slid into the "swamp" of formalism, skepticism ("cynicism") and utilitarianism through their overdependence on logical forms and rhetorical techniques.

In China, the first group of professional teachers come from the school of Confucianism founded by Confucius, whose fundamental philosophy is quite different from the school of sophists. For instance, Confucians argued that people "who are clever speakers and maintains 'too-smiley' faces are seldom humane individuals" (The Analects, Ch.1), while those "with firmness, strength, simplicity and caution in speaking" are "close to humaneness" (The Analects, Ch.13). It is right to say Confucianism, of which moral inquiry is identified as the aim of education, has never had the tradition of "lecturing pedagogy" but rather is the first educational school all over the world to set up a pedagogy of "listening".

The tradition of "lecturing" pedagogy in China is established by the school of legalism. One typical member of this school Han Fei elaborates:

Therefore, in the state of the enlightened sovereign there is no literature written on bamboo slips, but the law is the only teaching; there are no quoted sayings of the early kings, but the magistrates are the only instructors; there is no valour through private swords, but slaughter of the enemy is the only courageous deed. As a result, the people, within the boundary, when practicing persuasion and eloquence, always conform to the law; when up and doing, they always aim at meritorious services; and when pretending to valour, they always exert themselves in the army. (Five Vermin: A Pathological Analysis of Politics. In Han Feizi, 2007, p.273)

Here the ideas of law as the only teaching, magistrates as the only instructors, and slaughter of the enemy as the only courageous deed are actually an extension and enactment of the earlier theory of "unifying education" in The Book of Lord Shang. This book says :

The way in which a sage administers a state is by unifying rewards, unifying punishments, and unifying education. The effect of unifying rewards is that the army will have no equal; the effect of unifying punishments is that orders will be carried out; the effect of unifying education is that inferiors will obey superiors (Rewards and Punishments, The Book of Lord Shang, 2009, p.138).

In a deep sense, the school of legalism has straightly merged education with political governance. The so-called "unifying education" denotes the unionization of intellectual and axiological standards for education and represents an "absolute correctness" and "supremeness", which finds its base in the idea of "Sage King"(sheng jun). From the eyes of legalists, "the "Sage King", controlling rules of everything, builds up a doctrine for his people to follow with no permission of any critique or "independent opinion" challenging the authority of the King (Yu, 2004). Hence, the nature of "the theory of unifying education" is a political attitude of "revering emperor while humbling liegeman" and a power structure of "the down obeys the orders from the up". It is by those legalists that an educational tradition of "anti-intellectualism" was first developed which declares education as a process of preaching truths and receiving 
behavioral norms, and rewards and punishments as the nuclear mechanism to guarantee effective educational outcomes - all have laid a solid foundation for the pedagogy of "lecturing".

The exploiters of such tradition are not limited to legalists, they include also those Confucians who served as instruments for feudalistic governance. ${ }^{1}$ Since the time of the Han dynasty, the "marriage" between Confucianism and Legalism has contributed powerfully to the continuation of the "lecturing" tradition in education. For the purpose of pleasing and catering to rulers, Confucians in the Han dynasty consciously incorporated the ideology of "revering emperor while humbling liegeman" into their philosophies, namely "mingling ancient ritual and Qin system" (Biographies of Liu Jing and Shusun Tong, in "Records of the Grand Historian"), therefore initiating a long journey of "the legalization of Confucianism". In addition, "a large number of legalists lifted their faces to become Confucians which accelerated the legalization of Confucianism" (Yu, 2004). Without question, the legalists "Qin system" stands for the substance, whereas Confucian "ancient ritual" is merely its ectal form. Through the policy of "solely revering Confucianism with the rejection of all other philosophies", the boom of "dogmatization of Confucianism" and the emergence and spreading of "imperial examination system" (ke ju zhi) since the dynasties of Sui and Tang leading to the "utilitarianisation" of Confucianism, all Confucian classics were distorted as representatives of ideological authority and objects transmitted to students in education. Thus the tradition of "lecturing" pedagogy was enormously intensified.

By means of logical inquiry and the nurturance of students' rhetoric skills, western "sophists" sought indirectly for political power, Chinese legalists and the "legalization of Confucianism", by contrast, treated the demand of social governance and political power as explicit objectives of education. This is the significant way in which the tradition of "lecturing" pedagogy in western culture and that in China are distinguished.

The theoretical system of "lecturing" pedagogy in the West has been established since the Renaissance, particularly after the Enlightenment Movement. In the period of the Renaissance, the publication of John Amos Comenius' book, The Great Didactic, signified a preliminary establishment of the theory of "lecturing" pedagogy and also prepared for the future development of such theory in western countries. In order to understand better the meaning of "lecturing" pedagogy disclosed in this essay, we have to retrospect social, religious and culture backgrounds of the Renaissance, and especially the interrelatedness of Comenius' educational idea and "Ramism" (Doll, 2005; Hamilton, 1990; Ong, 1983; Hua, 2009). Honored as a "great scholar and beloved martyr" (Doll, 2006, p. 86), Petrus Ramus was one of the most influential humanists, thinkers and religious and educational reformers in the Renaissance. His philosophy could be summarized as "the supremacy of method", meaning "all ascertainable knowledge" can be taught through "the one and only way". The famous American curricularist William Doll generalizes Ramism into following four pivotal aspects: (1) accepting the notion that knowledge can and should be atomized, structured for "ascertainable results", (2) believing a simple and shallow presentation is the best for learning, (3) preferring the dialectical over the investigatory, and (4) assuming there's indeed "a best way", "the one and only way" (Doll, 2005, p. 28). This is obviously the first universalistic methodology in modern times. Such method "starts with universal propositions (those recognized by all as natural and valid) and is applied, universally, to all arts (subjects)" (Doll, 2005, p.

\footnotetext{
${ }^{1}$ Professor Yu Ying-shi has named the phenomenon of the politicalization of Confucianism and the "marriage" of Confucianism and Legalism after "legalization of Confucianism". See his paper Anti-intellectualism and Chinese political tradition: A dispersion and convergence of political philosophies of Confucianism, Legalism and Taoism, in his book Historical and literary traditions and cultural construction, (2004, pp.150-195).
} 
59). Certainty, simplicity, efficiency are typical characteristics of Ramism and its methodology.

The didactic method of Comenius was the by-product of Ramism. Comenius constructed his curriculum theory from the perspective of Ramus' epistemology where knowledge was thought ascertainable and reducible. Comenius' opinions on teaching also inherited Ramus' assertion "to teach ascertainable knowledge in the one and only way", for example, he acknowledged teaching is to enable students to learn what is already known. His way of teaching is "the whole art of teaching all things to all men", and is "an easy and sure method" (Keatinge, 1907, p.3). His well-known inventory "class teaching system" reflected the requirement of "efficiency" of Ramism as well. Comenius said, "since a brick-maker burns many bricks at one time, it is not only possible for one teacher to teach several hundred scholars at once, but it is also essential" (Keatinge, 1907, p.3).

The honor of inventing the first systematic pedagogy of "lecturing" should be bestowed to Ramus and Comenius. Such pedagogy not only succeeded the tradition of logical formality and speculation from the "school of sophists", but also reflected the pursuit of "efficiency" of the rising, merchant middle class, and notably the axiology of Protestants and Puritan. Being a preeminent religious reformer and Protestant, Ramus held a skeptical and critical attitude towards Catholicism's traditional "God", and advocated a more involved, powerful and "omniscient and omnipotent" "God". "The one and only way" complied with a fixed order from generality to particularity and owned peculiarities of simplicity, powerfulness and efficiency The "method" here becomes a counterpoint of "Holy Spirit", just as Increase Mather revealed: "once all forms of connection are specified and named and then ranged in schematic series, man has a logical transcript of the wisdom of God in so far as that is manifested in creation" (Doll, 2005, p. 27).

The second systematic "lecturing" pedagogy was born after the Enlightenment and represented by the publication of Johann F. Herbart's book Allgemeine Pädagogik. While Comenius's didactic method is considered having too many traces of religion and speculative philosophy, Herbart's "lecturing" pedagogy appears more refined and scientific. As the Germany educational historian Friedrich Paulsen claimed, "Herbart's theory of education" and "the scientific theory of education" were, for a long time, synonymous terms" (Paulsen, 1976, p.245), Herbart is recognized as "the founder of scientific education" (Qilong, 2002, p. i), not only owing to his strong dependence on psychology, but because his pedagogy was built upon Enlightenment rationality and its affiliated "sensory empiricism". "Sensory empiricism" claims human's perception is the "mirror" of nature, to make reflections of nature more accurate, one has to keep his or her sensory "mirror" as "clean" as possible, meaning that the more passive our sensations are, the more accurate will the reflection be. Scientific knowledge deemed "objective" and "confirmative" comes from the manufacture and refinement of sensational experience. Everything from nature is traceable according to its law, and so is the transmission of knowledge in the process of teaching. The "law" for education, in the eyes of Herbart, is "the formal steps of instruction". In this way, the dream of "teaching all ascertainable knowledge through the one and only way" Ramus and Comenius advocated found its foundation in epistemology and psychology and was elaborated by them in concrete and operational terms.

I once argued to distinguish "two Ramus", "two Comenius'" and "two Herbarts"": on one side of the scales stands Ramus and Comenius who upheld the spirit of humanism and respecting human nature, and Herbart who aspired after rationalism and individual freedom, on the other lies another Ramus and Comenius who proclaimed a universalistic methodology, and another Herbart who designed a mechanical and rigorous system of instruction (Hua, 2009). In like manner, the "lecture" pedagogy they developed has double peculiarities: in terms of its origin, it does inherit the spirit of 
humanism, Enlightenment rationalism and the respects to humanity and personal freedom; but seen from its outcome where teaching and schooling are equalized to "the lecturing of subject knowledge" and suffer from the "illness" of universalism and formalism leading to a broken linkage between themselves and epistemological inquiry and creativity, such a pedagogy eventually heads for the opposite of humanism and enlightenment mentality.

In the western world, "lecturing" pedagogy is generally going downward in spite of a short-while "resplendence" after the time Herbart lived. From the late 19th century to the early 20th century, instrumentation, technological rationality and utilitarianism chasing "productive efficiency" and "social efficiency" as the result of world climactic "industrialization" were prevalent and spread over all. Their manifestation in education is an emphasis on pre-determined objectives and educational efficiency, such as the "efficient teaching" epidemic in United States in the 1920s and 1930s. At the climactic period of the "social efficiency movement", some schools even adopted a management system based on "piece rate" where teachers were paid in light of their amounts of objectives they achieved in lessons. The idea of "education as manufacture" and "school as factory" plus the "behavioral psychology" facilitated the popularity of "lecturing" pedagogy namely "scientific" education exhibiting itself particularly as "objective model" and efficient teaching in the fields of curriculum and instruction.

In the shift of time, a new spirit arose leading to the decline of "lecturing" pedagogy in the West. Since the late 19th century and early 20th century, human society has entered into an epoch of "post-Enlightenment" when enlightening rationality with its outcomes like sensory empiricism, universalism and formalized methodology becomes an object of reflection, critique and transcendence, when education and teaching begin to incorporate with intellectual inquiry and creativity as a whole, both making "lecturing" pedagogy, marked by "knowledge transmission", out of date.

In specific social contexts, a pedagogy of "lecturing" has been re-proposed by supporters of some educational thinking genres (i.e. conservative "essentialist" and "neo-liberalist") and some educational policies (i.e. "back-to-basics movement" in the United States in the 1970s), but it rarely regresses to its original mainstream status, despite its changed "face" compared to the "lecturing" pedagogy at the time of the Enlightenment.

Current Chinese pedagogy of "lecturing" is copied from "Kaiipob pedagogy" in the former Soviet Union (Hua, 2009). "Kaiipob pedagogy" is the complex mixture of Herbart's "lecturing" pedagogy, educational tradition, mainstream ideology (especially "Stalinism") and demands of political ruling in the former Soviet Union (Yang, 2007). Likewise, our introduction and dissemination of such pedagogy in the 1950s was the requisition of political struggle and ideological control. During the 1980s "Kaiipob pedagogy" was further developed and generated the so-called "special epistemology of teaching" in China (Wang, 1985, 2002). Not until the 1990s did Chinese educators start to epoché mainstream ideology and to animadvert upon "Kaiipob pedagogy" and its derivations in respect of China's own educational theory and practice. The latest wave of such animadversion is taking place in the early 21st century in the context of new curriculum reform, of which a typical works is Professor Zhong Qiyuan's book The critiques on Kaiipob pedagogy (Zhong, 2009).

Seen from the surface, it is the reliance on political strength and its feature of "teaching manual" operable for teachers that accounts for the swift spreading of "Kaiipob pedagogy" all over the country, but if by taking a closer and deeper perspective, we will realize this prevalence actually has its cultural root, which is the pedagogy of "lecturing" created by legalists and the "legalization of Confucianism". The main characteristics of "Kaiipob pedagogy", like the mainstream ideology approach (education serves politics), stresses mastery and training regarding knowledge, skills and norms, leading to the oppression and dominance of students. Universal laws, 
standards, models and contents, are all congenial and homogeneous to the theory of "unifying education" in Legalism. In consequence, in order to rebuild our educational theory and practice, besides the sincere reflection on problems of "Kaiipob pedagogy" and its derivations, we need to thoroughly rethink the pedagogical tradition of "lecturing" in our Chinese context.

What implications have been brought to us from the tradition and reality of "lecturing" pedagogy in both the West and China? First, "lecturing" pedagogy sticks to a control-based axiology. Both western logicism and instrumental rationality, and Chinese political oppression of "all-in-one", attempted to manipulate and compel younger generation's free minds to submit to existing power relation and cultural order in virtue of external and upper power. Secondly, "lecturing" pedagogy underscores an "anti-intellectualism" or "reflectionalism-based epistemology". "Anti-intellectualism" is hostile and depreciated to the inquiry process of knowledge and intellectuals who are professional at pursing such process, and substantially an "epistemology of antiepistemology" due to its attitude of "no discussion, no debate" stood for by Chinese legalists. This "reflectionalism-based epistemology" is the product of enlightening rationality identifying knowledge and cognitive process as the "reflection" (or representation) of the human brain to the "objective world", and that the only thing left after a "correct reflection" (that is a "truth") is found in dissemination and application with no consideration of inquiry any more. The common peculiarity of "antiintellectualism" and "reflectionalism-based epistemology" is to despise and clamp down the inquiry process of knowledge, thus preparing for "direct lecturing". Finally, "lecturing" pedagogy believes in a methodology of universalism proclaiming there is one educational method universally effective and applicable to all contexts, namely "lecturing method".

By this token, although having a long history and popular with the development of "science-technology-industry", "lecturing" pedagogy, in consequence of its "controlism" axiology, epistemology of ignoring intellectual enquiry and creative process, and teaching a methodology of universalism centering on "lecturing", has reduced education to an oppressive and manipulative process towards an individual's mind through the transmission and dogmatization of knowledge and skills, and thus covers and alienates what education essentially is. The point is not the utilization of "lecturing" as one of the methods for classroom teaching, but the misuse of "lecturing" to the extent that the nature of education is therefore concealed. From the perspective of "lecturing" pedagogy, even "lecturing" itself is distorted. The German philosopher Heidegger once pointed out in one public speech that hearing is the essence of and has more priority over lecturing (Heidegger, 1997). Hence recovering the "listening" nature of education and walking towards "listening" pedagogy is the necessary way of rebuilding education and pedagogy in the West and in China.

\section{Historical development of "lecturing" pedagogy}

Through the ages, each educational philosophy with progressive characteristics espouses the integration of research on students with pedagogy itself. Confucius was considered as the greatest teacher in China's 2,500-year history, partly because he was the "knower" of his disciples. "I will not be afflicted at men's not knowing me; I will be afflicted that I do not know men" (The Analects, Ch. 1), said Confucius. He knew all his disciples, not only their personalities, but their cognitive styles and thinking peculiarities: "Chai is simple. Shen is dull. Shi is specious. You is coarse" (The Analects Ch. 11). This is the typical description of disciples' personalities. Each discipline had its own specialty: "Distinguished for their virtuous principles and practice were Yan Yuan, Min Zi Qian, Ran Bo Niu, and Zhong Gong; for their ability in speech, Zai Wo and Zi Gong; for their administrative talents, Ran You and Ji Lu; for their literary acquirements, 
Zi You and Zi Xia" (The Analects, Ch. 11). This portrays the cognitions, thinking styles and interests of disciples. Confucius' way of listening to and research on students is manifested by the development of students themselves in the teaching process, and by the questions with features of eternal openness and multiple answers corresponding to students' different characters.

Similarly, Socrates in ancient Greece synchronized teaching, listening to students and seeking for truth together. Socratic dialogue or the "art of midwifery" has two significant traits: one the one hand, in face of the world, knowledge and truth, a teacher "realizes his or her ignorance completely" (Fakun, 1994); on the other hand, in front of students, the teacher is aware of the fact that knowledge and truths are internalized into students' spirits. "I realize I'm fully ignorant" is not a stance pretending to "know nothing" while in fact "knowing something", but is a sincere and courageous acknowledgment of "knowing nothing". Hans-Georg Gadamer once stated, "among the greatest insights that Plato's account of Socrates affords us is that, contrary to the general opinion, it is more difficult to ask questions than to answer them". "In order to be able to ask, one must want to know, and that means knowing that one does not know" (Gadamer, 2004, pp. 356-357). When "realizing him- or her-self is indeed ignorant", the teacher is transformed from a "teller" to a "questioner", from a "lecturer" to an "explorer" of knowledge and truth. Compared to other explorers, the teacher as an explorer has his or her own uniqueness: he or she is not only the explorer of the world, knowledge and truth, but the one understandable for students, combining these two types of exploration into an entirety. The deep implication of Socratic "art of midwifery" lies in the following three aspects: firstly, the teacher and the student are equal to each other as they both are explorers of the world, knowledge and truth; secondly, the teacher has trust in students' competency of creating knowledge and discovering truth, since knowledge and truth are constructed internally rather than inserted from outside, just like fetal growth and development; lastly, the teacher's questioning is not only a process of study on and understanding of students, but a facilitation process of developing students' own perceptions. In this case, a teacher's listening to and understanding of students becomes inseparable from his or her teaching. As Dr. Zhong Jianwei concludes, "Socrates is a teacher filled with teaching wisdom and expertise reflected not by his lecturing and question-answering, but by his dialectic skills and techniques, his capability of listening and his sensitivity of questions" (Zhong, 2010). In sum, Socrates is apparently a forerunner of the tradition of "listening" pedagogy in the West.

From the Renaissance to the Enlightenment movements, and into the 19th century, "listening" pedagogy had earned its axiological foundations, although its theoretical system had never been comprehensively established. The glorication of humanism in the Renaissance, the respect and eulogization of intellectual freedom and human rights in the era of the Enlightenment, brought forth the modern idea of childhood and opened up a great journey of educational modernization and democratization aiming to do research on and emancipate children. Rousseau created the first "theory of discovery teaching" in history stressing the necessity of listening to and research on students. In the beginning we have to study our students as we don't understand them at all; "Childhood has its own way of seeing, thinking and feeling" (Rousseau, 1990), hence teachers should help students to re-discover science by themselves rather than to repeat current formulas adults pre-designed. It is because of such insightful views that Rousseau was counted as a "bosom friend" of Piaget who thought Rousseau should be forgiven despite the rest of his other opinions and deeds (Piaget, 1990). Since then, many other educators like Pestalozzi, Fröbel and Diesterweg succeeded to the tradition of studying and emancipating children, and initiated a tide of educational exploration and experiments lasting almost one hundred years. Nevertheless, just as narrated before, due to the "sensory empiricism" stemming from the enlightening rationality and the 
restrictions of social cultural backgrounds of the age, a pedagogical system of "listening" could not be successfully founded.

The first system of "listening" pedagogy was built by American philosopher and educator John Dewey. Dewey said, "The connections of the ear with vital and out-going thought and emotion are immensely closer and more varied than those of the eye. Vision is a spectator, hearing is a participator" (Dewey, 1927). Dewey constructed his theory upon a new axiology, epistemology and methodology: at the level of axiology, it transcended the separation and gap among different individuals and groups, between people and their society, and the nature, and maintained the interaction, co-sharing and organic mingling of each party; in terms of the way of cognition and thinking, it moved from "bystander epistemology" (a dualism separating subject and object, knowing and doing where humans get to know the world as "bystanders") to "participatory epistemology" (a continualism integrating subject and object, knowing and doing where humans start to know the world as "participators" ) ; from the aspect of methodology, it transferred from "operationalism" underlining mechanism, close-mindedness and linearity to action, problem-solving and inquiry full of wisdom. Upon these corner stones, Dewey set up his own system of "listening "pedagogy which was opposite to "lecturing" pedagogy, refracting autocratic system and its ideology, and led education into a new historical phase --- an era of "post-enlightenment" and democracy. Such "listening" pedagogy has the following two typical characteristics. In the first place, education is a process of participating in the society and life. Through a mechanism of mutual-listening, education becomes a process of interpersonal interaction and social communication, and school becomes a community of democracy; through the participation of "hearing", education becomes a positive strength blending into and transforming the complex society. In the second place, education is a process of research and experimentation. On the basis of listening to and studying children, education creatively alters academic knowledge into children's own experiences, by letting them join in the process of exploration, experimentation and research on subject matters, and turns to be a process of creating instead of transmitting and receiving knowledge and skills. Considering the social background at that age, Dewey's "listening" pedagogy was in fact one part of the great educational experiment named "progressivism" in the United States.

The second scholar who created a systematic framework of "listening" pedagogy is Jean Piaget. Piaget is one of the founders of European structuralism and genetic epistemology, the western movement of cognitive psychology and constructivism, and one of the leaders of the "new educational movement" in Europe and international educational reform. ${ }^{2}$ In one interview, Piaget made a profound claim, "to me, education signifies the cultivation of innovators" (Piaget, 1990). That the innovator is the ideal figure in a democratic time is a consensus for the "progressive educational movement" and the "new educational movement" sweeping over the whole European continent and U.S., and for all other educational democratic movements. The central point is: How can we have such an innovator through education? Right at this point Piaget makes a groundbreaking contribution and constructs his "listening" pedagogy. In the mind of Piaget, a human's cognitive process is a mixture of assimilation and accommodation meaning that all of us take experiences into our own schemes, structures and previous understanding, and "we cannot assume that an experience the meaning of which seems clear to us will have that meaning to anyone else" (Duckworth, 2005). How students understand academic knowledge or even a common phenomenon in the world is an issue worthy of for-ever investigation. A pedagogy aiming to develop innovators is precisely based on such investigation. But the question is how? Piaget proposed a

\footnotetext{
${ }^{2}$ Piaget was the director of the International Bureau of Education in Geneva from 1929 to 1967, and thus was one of the path-breakers in the enterprise of international education.
} 
methodological suggestion called "clinical interviewing" or "the clinical method", which essentially consists of "engaging children in talking about their ideas" (Duckworth, 2005). What matters to educators most is their listening to students' voice, which shapes education as a way of listening and research. Later on, Piaget's disciple and life-long colleague Barbara Inhelder invented a new terminology: "critical exploration" ${ }^{3}$. "Listening" to children is not merely an "interview", but an exploration, including children's exploration of academic knowledge and real worlds, and teachers' (or other adults') exploration on children's ideas. Hence, "critical exploration" is a further development of "clinical interviewing" by confirming the values "to the work of devising the situations in which children are called upon to think, and to talk about what they think" (Duckworth, 2005). Such a notion was finally adopted by Piaget in the sunset of his life.

The primary contribution of Piaget's "listening" pedagogy is the transformation of education into child (or student) study by designing certain contexts where children could be fully engaged and their interpretations could be heard with the intervention and help of adults. Such a method, in the eyes of Piaget, is the fundamental approach to foster innovators imbued with an "experimental spirit". Piaget argued:

Absolutely nothing is done to teach the child the spirit of experimentation. He has lessons, he sees experiments demonstrated; but seeing them is not the same as doing them for himself. I'm convinced that one could develop a marvelous method of participatory education by giving the child the apparatus with which to do experiments and thus discover a lot of things by himself. Guided, of course. But in fact it would have to be a professional who could see how this would work in practice. (Bringuier, 1989, p. 131)

It is the participation and experimental spirit that constitute common purports in "listening" pedagogy of Dewey and that of Piaget.

At the present age, the scholar who further develops Piaget's "listening" pedagogy is Eleanor Duckworth, a student of Piaget and Inhelder and a famous professor from the graduate school of education in Harvard University (Duckworth, 1996, 2001). Firstly, she reinterprets the essence of a human's development. Piaget was interested mostly in documenting characteristics, structural elements and regularity of different developmental phases, whilst Duckworth turns deeper to the understanding of uniqueness of every individual under development. She asserts that the nature of intellectual growth is that everyone, no matter in which stage or level, has his or her irreplaceable "wonderful ideas". "The having of wonderful ideas, which I consider the essence of intellectual development, would depend instead to an overwhelming extent on the occasions for having them" (Duckworth, 2001, p. 181). Any theory, as long as it attends to and protects the uniqueness of each person's development, has pedagogical peculiarity. Duckworth's theory is definitely a true educational theory.

Secondly, she unfolds "listening" into a teaching methodology combining teaching and research. Piaget spent most of his time on the psychological development of children, whereas Duckworth concentrates on classroom teaching practices and is thus known as "Piaget in classroom". The core of her teaching methodology is "to listen, to have our learners tell us their thoughts" (Duckworth, 2001, p. 181). Since "the curriculum is explorable, and the pedagogy asks the students to express their thoughts about it" (Duckworth, 2005, p. 261), the "classroom was a good place to be a researcher into children's thinking [...] the very process of doing the research was a teaching process, as well" (p. 260). To conduct teaching research in classrooms, to listen to teachers' voices and to listen to what students say, to evaluate their working

${ }^{3}$ Duckworth states Inhelder used the term "critical exploration" for the first time in her book Learning and the development of cognition. See Inhelder, B., Sinclair, H., \& Bovet, M. (1974). Learning and the development of cognition (S. Wedgewood, trans.). 
effectiveness in accordance with how much positive affects any research produces on the development of both teachers and students, and to change educational research into responsible research, are the critical implications Duckworth's theory. In addition, as for school teachers, Duckworth suggests "Listening to students" thoughts is a good way to teach. And the very process of teaching is a research process, as well" (p. 260). To eliminate the adverse properties of teaching (e.g. mechanization, close-mindedness, trivialness, routinization and simplification), to mingle him- or herself with students while listening to student's voices, to professionalize own thinking frames by stimulating the development of students' ideas, to cultivate a sensitivity of problems and profoundness of thinking by transforming teaching into a research process exhibiting his or her own uniqueness, to make her- or himself a teaching researcher with independent thinking he or she is fully confident of, are crucial implications of what Duckworth's theory and actions offer to teachers under professional development.

Thirdly, she builds curriculum planning upon the ideas of teachers and students, and respects the complexity of academic knowledge and the outside world. Duckworth says: "The purpose of developing booklets at all is that teachers and children start producing and following through their own ideas, if possible getting beyond needing anybody else's suggestions" (Duckworth, 1996, p. 8). From her perspective, the kernel of curriculum is the idea that both teachers and students emerge and develop themselves within the process of teaching; as a result, curriculum is not only fused with teaching but is the "unexpected" in substance just as in teaching. The planning of curriculum is to uncover mysteries of the world and every subject matter, not to make up a system hiding and sealing the knowledge and world, thus we curriculum developers ought to overcome a tendency of "oversimplification" and to keep the complexity of each subject and the whole world. Duckworth elaborates:

Once we are willing to accept the real complexities of subject matter, we find that they lurk even in the most unlikely places. One of the abilities I seek to develop in teachers is the ability to recognize unsuspected complexities in what seems like straightforward, even elementary, material [...] It is always in confronting such complexities that one develops real understanding (Duckworth, 1996, p. 136).

Taken together, through the intermediary of listening, Duckworth unifies teaching and student research, curriculum and the ideas of teachers and students, and makes students' growth and teachers' professional development happen simultaneously, leading to a new stage of "listening" pedagogy.

If Dewey, Piaget and Duckworth are believed to have systematically developed the thinking dimension of "listening" pedagogy, since the middle of the 20th century, phenomenology, existentialism and hermeneutics have also significantly impacted the evolution of the experiential dimension of "listening" pedagogy. The common pursuits of Maxine Greene's "consciousness" pedagogy, Nel Noddings' "caring" pedagogy, William Pinar's "currere" and Max van Manen's "pedagogical experience", are as follows: the goal of education is to seek for the meaning of life presenting and narrating itself; only by being a listener, either a teacher or a student can really experience his or her meaning of life. Max van Manen states: "an authentic speaker must be a true listener, able to attune to the deep tonalities of language that normally fall out of our accustomed range of hearing, able to listen to the way the things of the world speak to us"; "Whoever wants to become acquainted with the world of teachers, mothers, fathers, and children should listen to the language spoken by the things in their lifeworlds, to what things mean in this world" (van Manen, 1990, pp. 111-112). To let education return to the life world and to experience the life meaning of education by listening is what "listening" pedagogy informed by existential phenomenology aspires after.

The thinking aspect of "listening" pedagogy is to regard "listening" as a research and problem-solving attempting to excavate secrets of birth and development of human ideas, whilst its experiential aspect is to see "listening" as the experience and pursuit of 
meaning trying to disclose mysteries of human's awakening consciousness, life experience and the emancipation of individuality. The former can make our lives more powerful while the latter more meaningful, only in the way of integrating both sides could a more complete "listening" pedagogy be constructed.

\section{Characteristics of a "listening" pedagogy}

"Listening" pedagogy is to build education on the basis of "listening" and to make education a process of creating knowledge and seeking for life meaning within the interactions and fusions between a teacher and his/her students, human and the world. Such pedagogy attempts to reconstruct education at the levels of axiology, epistemology and methodology.

\section{Axiology of "Listening" Pedagogy}

A Human is a unique being capable of listening and of forging relationship, obtaining understanding and looking after meaning through such listening. Hence, education should be executed by listening and needs to cultivate people who are willing and able to listen.

Pedagogy is basically a child study. To address the question of what education is must take consideration of what childhood is and, more rudimentarily, of what mankind is. In his reputable book Being and Time, Martin Heidegger (1996) asserts "The human being shows himself as a being who speaks. This does not mean that the possibility of vocal utterance belongs to him, but that this being is in the mode of discovering world and Dasein itself"(p.155). The being of human is to reveal the world and him- or herself, as a "revealer", a human is embodied and exists in the world and ego he or she reveals. To "reveal" refers to understand, discover and create, and meanwhile to hear the voice of what has been revealed, which determines human as a being capable of listening. "Dasein hears because it understands" (p. 153). "Only he who already understands is able to listen" (p. 154). Therefore, listening is a course of opening up, achieving and manifesting a human's nature, and is based on an "existentially primary potentiality" ( $\mathrm{p}$. 153).

What's the relation between listening and speaking? In Being and Time, Heidegger points out, "The connection of discourse with understanding and intelligibility becomes clear through an existential possibility which belongs to discourse itself, hearing. It is not a matter of chance that we say, when we have not heard "rightly", that we have not "understood". Hearing is constitutive for discourse" (Heidegger, 1996, p. 153). It is inferred that listening is not just a part of discourse but continually constructing discourse per se, discourse presents and accomplishes itself right through listening. People could speak only after they hear the voices of "differences" and "silence", the voices of beings of human and the world, so listening is the premise of and lays foundation for speaking, without the base of listening, "speaking" won't be true speaking. As to the speaking or lecturing in education, we can only call them "soundmaking" as they barely have such a base. In general, speaking is the further growth and development of listening. Listening also implies freedom. Listening is the presence and unfolding of the understanding nature of being human, and of the nature of others and things being listened to, and is the fusion, correspondence and dialogue between listeners and the world (s) he lives in. This is precisely the accomplishing process of freedom that is the presence of essence and "letting beings be" (Heidegger, 1998, p. 146).

"Listening" is the wisdom tradition of the Chinese nation and embodies the spirit of time. The Chinese nation is a nation fond of listening. The ideal person, a "sage" in the ancient Chinese tradition, persistently adored, was good at listening. From the perspective of etymology or philology, Chinese words "sage" and "hear" come from the 
same graph (Jinglin, 2002). "The ancient pronunciations of the two graphs were similar and there are examples of their being used for one another in ancient texts" (Xigui, 2000). As we can see, both "sage" and "hear" having the same origin signify the interconnectedness of human and world. The first philosopher who elaborated the difference and similarity between listening and looking might be $\mathrm{Zi}$-si, one of Confucius' disciples. In his book $\mathrm{Wu}$ Xing, $\mathrm{Zi}$-si indicated "It is wise to know by watching while sage to know by hearing"; "Tao is the sageness hidden in hearing"; "brightness is the knowledge hidden in vision". Here Zi-si has depicted the differences of two sets of categories: "watching" and "wisdom", "hear" and "sage". Later on, Mencius distinguished "to know by hearing" and "to know by watching", saying "From king Wen to Confucius were 500 years and more. As to Tai Gong Wang and San Yi Sheng, they saw Wen, and so knew his doctrines, while Confucius heard them as transmitted, and so knew them" (Mengzi, Ch. 7, II). Then what are the connectedness of "listening" and "watching", "sageness" and "wisdom"? Wu Xing answered, "If a man is not astute he will not be bright; if he is not sage, he won't be wise; if he's not wise, he lives without virtue; if he's not virtuous, he won't feel easy; if he feels uneasy, he won't be happy; if he's unhappy, he is lacking goodness".

Only by listening to the unending lives of every being in the world could he be understood, as it connects humans with the world. "To know by hearing" refers to a cognitive approach in which understanding is attained through listening, and the fusion of human and the world is pursued. This is a vision Chinese ancient philosophers call the "unity of heaven and man"(tian ren he yi) that only "sages" can achieve. In contrast, "to know by watching" denotes another (lesser) intellectual way where understanding is received by watching but where the human is separated from the world, and thus the world becomes an object being watched, observed and studied. Therefore, ancient Chinese thought underscores "no sanctity, no wisdom": "sanctity" is the root and basis, while "wisdom" is the development and growth of "sanctity".

This "unity" suggests Chinese traditional culture is a culture of listening. It emphasizes the priority and fundamental role of listening, and the integration of listening and watching, so that the fusion of "knowledge of listening" and "knowledge of watching", "sanctity" and "wisdom" can be achieved. One Chinese scholar, Li Jinglin, defines such a way of thinking as "the embodiment of vision in hearing", and further points out, "Both Taoism's 'nameless' (wu ming) and Confucianism's 'unconcealedness' (jie bi) attempt to eliminate the symptom of immobilization of words and civilization, and to help them regress to their original holistic openness. It is rightly the purpose for Confucians to connect the world and human with the concept of sage, and to include vision into astuteness' (Jinglin, 2000, p. 164).

In terms of the relationship between listening and watching, the western culture has a quite different view from Chinese culture. In his book "Metaphysics", Aristotle states:

\begin{abstract}
All men by nature desire to know. An indication of this is the delight we take in our senses; for even apart from their usefulness they are loved for themselves; and above all others the sense of sight. For not only with a view to action, but even when we are not going to do anything, we prefer seeing (one might say) to everything else. The reason is that this, most of all the senses, makes us know and brings to light many differences between things. (Aristotle, 1983, p. 1)
\end{abstract}

The cognition Aristotle acknowledged for western culture is an emphasis on "visual sense" and "watching". Wu Shoupeng makes a footnote under the above quotation, "Greek philosophers always considered that the visual sense was the foremost among all senses" (Aristotle, 1983, p. 1). It is thus clear that the "cultural gene" ancient Greek passed down for western culture is the priority of vision that encompasses or even substitutes other senses, including hearing. Such cultural feature reached its peak after the Enlightenment movement. Dewey, Heidegger, Richard Rorty and Gadamer all argue the central theme of philosophy is to rethink the "visual culture" through the ages, to 
criticize the enlightening rationality and to reconfirm the importance of "listening culture". For instance, in his 1998 paper Über das Hören, Gadamer attempted to reestablish a "listening philosophy" within the framework of hermeneutics as a succession to what his supervisor Heidegger once argued (Gadamer, 2002). In like manner, the American philosopher David Michael Levin (1997) criticizes enlightening rationality and its "visual culture", and rebuilds the "listening philosophy" in his book The Listening Self. He indicates that the development of our hearing is to revive alienated meaning as a way of undertaking responsibilities for our future (Levin, 1997).

Not until the 19th century (especially 20th century), did western culture begin to echo Chinese traditional wisdom, when a "listening philosophy" was set up. This has shown not only a sharing trend in both western and eastern worlds, but also the unique role and value of Chinese "listening culture" in the historical process of rethinking enlightening rationality and moving forward to a "new Enlightenment".

After the Enlightenment, the expansion of and overdependence on rationality induced a separation and imbalanced development of creativity and morality (creativity grew rapidly while a sense of morality declined), and a loss of meaningfulness. At present, the big issue the western world is trying to settle is how to integrate creativity and morality and thus produce a truly "good work" (Gardner, Csikszentmihalyi, \& Damon, 2001). The thinking style and axiology of "including vision in hearing" and the fusion of "sanctity" and "wisdom" in Chinese wisdom tradition, of which nature is the combination of morality and creativity, could transform creativity as a growth of morality, and provide an intellectual source to resolve the problem of enlightening rationality, and eventually lay a foundation for the construction of "listening" pedagogy for the western world.

The ideal personality "listening" pedagogy desires to forge is an integration of creativity and morality, which means creativity is a "moral creativity "and morality is a "creative morality". It also fuses listening and speaking, "knowledge of hearing" and "knowledge of watching", and seeks for a free character by listening that constitutes a democratic (mutual-listening) society. In one word, what the "listening" pedagogy fosters is an individual able to be good at listening.

\section{Epistemology of a "Listening" Pedagogy}

Listening is the construction and reconstruction of knowledge; education is the collaborative production of knowledge by means of mutual-listening. Such a function of listening is exhibited within the following two aspects.

First, meaning is experienced in listening. On the one hand, people place themselves in the world and consider themselves part of the world; they are the "being in the world" and "worldliness" is an indelible feature of them. On the other hand, the world has been "humanized" as it stands within a human's soul and unwraps itself through the listening of a human. In addition, human's listening is part of world's calling and constructing the calling; humans attain and create meaning in their experiences. These are the common grounds for the "unconcealedness" (jie bi) of Confucianism, the "namelessness" (wu ming) of Taoism, Husserl's idea of suspending judgments to "reveal" the world in people's intuitive consciousness, Heidegger's "hearing is constitutive for discourse" and Gadamer's " understanding proves to be a kind of effect and knows itself as such" (2004, p. 336).

Second, thinking is produced in listening. Facing various dilemmas and hazards (e.g. illness, death, natural disasters, wars, interpersonal conflicts, family traumas, etc.), every person seeks for security in two ways: either escaping from perils, or studying them and finding solutions (Dewey, 1929). By listening people involve themselves in problems, understand the reasons leading to the problems, and examine hypotheses of addressing problems in action, in consequence, their personal experience, knowledge 
and thinking is accumulated, their abilities of problem-solving and creativity are developed. From Dewey's "participant epistemology", to Piaget's "clinical interviewing" and to "critical exploration" both Inhelder and Duckworth employ, listening is consistently identified as a process of generating ideas in problem-solving.

Education is rooted in the mutual-listening among people through which problems are collaboratively resolved and experience is pursued. In cooperation, the teacher and his/her students co-inquire issues in subjects and their lives, and hence develop their own thinking, knowledge and create a "public sphere" that is "a learning community". Education becomes the way of knowledge generation and "collaborative inquiry", framing a theory named "the integration of education and research". At the same time, in cooperation the teacher and his/her students co-experience themselves, the others, society, nature and culture, and evolve their affects of compassion, care, loves of life and knowledge Education thus becomes the way of meaning creation and communal life, forming another theory called "the integration of education and life". When combined, the thinking dimension and experience dimension of education turns out not only meaningfully but powerfully.

\section{Methodology of a "Listening" Pedagogy}

"Listening" pedagogy is a methodology for education but also for educational research where educational theory and research is syncretized with educational practice and action, an approach well embodied within Dewey's idea of "the oneness of knowledge and action", and the practices of Piaget, Inhelder and Duckworth. This pedagogy has four interconnected and mutual-permeated methodological aspects: listening, description, interpretation and action.

\section{Listening}

"If we listen, they will hear their own answers" (Duckworth, 2001, p.3). It is only when teachers become listeners that education will be rebuilt upon listening. An educational listening is to care about, attend to and engage in students' thoughts and experiences, teaching routines and events, phenomena in other educational environments, with an attitude of caring and accepting who is being listened, and an intellectual participation, understanding and research. For teachers, it is critically important to sincerely accept students' ideas with a willingness to explore its developmental history, to accept students' experience with an "empathic perception" and to allow students' idea and experience to grow at their own paces. With decades of listening experiences, professor Duckworth concludes: "Finding someone who was interested in their thoughts, people became avid learners, even in fields that had not interested them before. My ways of trying to follow their thoughts turned out to be excellent ways to excite their learning". I learned the importance and the challenge of listening well enough to understand what they were saying" (p.3).When listening becomes an attitude of caring and intellectual engagement infiltrating into the whole body and mind rather than merely a hearing through the ears, we shall have "the listening eye" and "the listening body" (Murray, 1979).

\section{Description}

"We learn to see a thing by learning to describe it" (Williams, 1961). Description is to write down what we have heard and observed as things really are, but still with understanding and creativity. Such a process requires wisdom and also courage, since people sometimes distort facts for the sake of their own benefits or due to some narrow prejudices, and deliberately misrepresent something under the adverse conditions or the pressure of dictators. Description also means not to hastily make evaluation and 
conclusion before the moment of listening and observing happens. It's always easy but arbitrary to measure the "goodness" and "badness" of a person, an event, an idea or action with a specific standard, by which the person or thing being measured will be likely to be covered, distorted or even destroyed as we don't really understand him/her or it. Description is not a "quantitative method" to categorize, generalize and deduce things like what natural scientists usually do, for it remains locating things into a prepared framework and thus hardly contributes to the revealing of things. Just as Heidegger argued, "description does not mean a procedure like that of, say, botanical morphology. The term rather has the sense of a prohibition, insisting that we avoid all non demonstrative determinations. The character of description itself [...] can be established only from the 'material content' [Sachheit] of what is 'described', that is ,of what is to be brought to scientific determinateness in the way phenomena are encountered" (Heidegger, 1996).

The question is how to describe? First, we should respect the uniqueness, complexity of the person or thing being described. P. F. Carini (2001) states, "the world is always larger than my conceptualization of it" (p. 163). Duckworth claims, "We need to make use of, take advantage of, the complexity of a subject matter if we are to help in the creation of classrooms were significant learning can take place" (Duckworth, 2001, p. 186). Albeit the complexity of the world could be atomized and reduced into pieces with conceptual frameworks and logical instruments, the pieces added together are not equal to the whole world. Therefore the first mission of descriptive research is to regress to the uniqueness and complexities of people and things. Second, the connectedness and continuity among people or things ought to be concerned. The world is a giant network, every one or thing is not isolated but stays in the history (the past and the future) of him, her- or itself, and in relationships with surroundings. Only backing to the history and living environment of the person or thing, we could truly understand him/her/it. Hence, doing a descriptive research requires an "attitude of continuity" besides the "mind of complexity".

Third, the perspectives of human or things are supposed to be respected. It is clear that the well-roundedness and complexity of a thing decides its "perspectives", and that the thing is varied owing to its unlimited perspectives. Such a view has two implications for the descriptive research: on the one hand, it is necessary to switch various perspectives to see the world differently and respect the differences between them in the process of description (Himley \& Carini, 2000); on the other hand, many describers constitute a community of inquiry to collaboratively describe the same person or thing in order for a deeper disclosure. To sum up, a descriptive research is a process of revelation, listening, understanding and creation of the object under inquiry through which the world becomes more and more perfect. It implies that humans not only have the courage and wisdom to repair the world destroyed, but are good at maintaining the world undamaged as it originally is (Hua, 2008).

\section{Interpretation}

The goal of interpretation is not to explain what the thing is, but to seek for human's freedom (Smith, 2000). Educational understanding reveals itself in interpretation referring to the reflection and discussion of what has been listened and described to discover hidden meanings. For teachers, interpretation means to stand at the side of students to understand the meanings students created and have them developed, and to speak what students demands to speak but haven't spoken. Teachers should give up the idea and action of "telling you correct answers" and move to study students' thinking and experiences, to let students confidently speak out what they want to say, by asking over and over again "what do you mean"," why do you think that", "could you please demonstrate what you thought" (Duckworth, 1996). "Listening" pedagogy requires teachers' interpretative wisdom, as sometimes they have to keep students moving 
forward at their own paces by repeating their questions or thoughts; sometimes they had better perplex students and lead them forward by questioning what students argued like Socrates. For students, interpretation denotes speaking out their own ideas and experiences in the context of problem-solving or meaning-pursuing. "Much of the learning is in the explaining" (Duckworth, 1996, p. 158). To explain is to "give birth to" ideas and experiences deepened day by day, in which way students make sense of the knowledge on their own.

\section{Action}

"An ounce of experience is better than a ton of theory simply because it is only in experience that any theory has vital and verifiable significance" (Dewey, 1997, p. 150). The "experience" Dewey highlighted here is an action built upon intellectual judgments, but how to measure the value or effect of listening, description, interpretation in an educational process? I believe the primary criterion is to check whether a new pedagogical meaning has been generated and the quality of teaching and learning has been improved. For teachers, action means to transform teaching into research, including their consistent research on students, collaborative research on subjects and lives between teachers and their students, students' research with the supervision of teachers. For students, action refers to changing learning into a process of problemsolving and meaning-pursuing, a course of learning to think and survive (Hua, 2010), where every student's personality could be opened out by morality and creativity mingled together.

In conclusion, the four aspects of "listening" pedagogy are fused together and in a "four-in-one" relationship, instead of lineally sequenced and non-regressive. In practice, they present themselves not independently, but from within a complex and dynamic organic totality. However, these aspects can only stand for a part of the whole picture of a "listening" pedagogy, the reasons for respective illustrations here is to deepen our understanding of particular elements, and to demonstrate that "listening" pedagogy is not only a new theoretical paradigm of pedagogy, but a reflective educational practice and action aiming to reform education.

\section{References}

Aristophanes (1954). A collection of Aristophanes' comedies. (Luo Niansheng, trans.) Beijing, China: People's Literature Publishing House.

Aristotle (2002). Metaphysics (J. Sachs, trans.) Santa Fe, NM: Green Lion Press,

Aristotle (1983). Metaphysics (Shoupeng Wu, trans.) Hong Kong, China: The Commercial Press.

Bringuier, J-C. (1989). Conversations with Jean Piaget. Chicago, IL: The University of Chicago Press.

Carini, P. F (2001). Starting strong: A different look at children, schools, and standards. New York, NY: Teacher College Press.

Dewey, J. (1927). The public and its problems. New York, NY: Henry Holt and Company.

Dewey, J. (1929). The Quest for certainty: A study of the relation of knowledge and action. New York, NY: Minton Balch \& Company.

Dewey, J. (1997). Democracy and education: An introduction to the philosophy of education. New York, NY: Free Press.

Doll, W. E., (2005). The Culture of Method. In W.E. Doll, M.J. Fleener, D. Trueit, \& J. St. Julien, (eds.) (2005). Chaos, Complexity, Curriculum, and Culture: A Conversation. New York, NY: Peter Lang.

Doll, W. E. (2006). Method and Its Culture: An Historical Approach. Complicity: An International Journal of Complexity and Education, 3(1), 85-89.

Duckworth, E. (1996). "The Having of Wonderful Ideas" and Other Essays on Teaching and Learning (2nd ed.). New York, NY: Teachers College Press.

Duckworth, E. (2001). "Tell me more": Listening to learners explain. New York, NY: Teachers College Press.

Duckworth, E. (2005). Critical exploration in the classroom. The New Educator, 1(4), 257-272. 
Fakun, Z. (Ed.) (1994). Collection of Educational Articles in Ancient Greek. Beijing: People's Education Press.

Gadamer, H.G. (2002). Über das Hören (About Hearing) (Pan Derong, trans.) In Cheng, Zhongying (Ed.). Ontological Hermeneutics II. Beijing, China: Beijing University Press.

Gadamer, H.-G. (2004). Truth and method. London: Continuum.

Gardner, H., Csikszentmihalyi, M. \& Damon, W. (2001). Good work: When excellence and ethics meet. New York: Basic Books.

Hamilton, D. (1990). Curriculum History. Geelong, Victoria: Deakin University Press.

Heidegger, M. (1996). Being and Time. (J. Stambaugh, trans.) Albany, NY: State University of New York Press.

Heidegger, M. (1997). On the way to language (Z.X. Sun, trans.) Hong Kong, China: The Commercial Press.

Heidegger, M. (1998). Pathmarks (W. McNeill. ed.) Cambridge, UK: Cambridge University Press.

Hegel, G.-F. (1983). Lectures on the history of philosophy II (He Lin \& Wang Taiqing, trans.) Hong Kong, China: The Commercial Press.

Herbart, J.F. (2002) General pedagogies and outlines of pedagogical lectures (Li Qilong, trans.) Zhejiang Education Press.

Himley, M. \& Carini, P. F. (Eds.) (2000). From another angle: children's strengths and school standards: the Prospect Center's descriptive review of the child. New York, NY: Teachers College Press.

Hua, Z. (2008). Teaching as description: a brief introduction of Carini's teaching philosophy. Global Education, 37(5), 9-17.

Hua Z. (2009). The intellectual tradition of teaching method. Global Education, 38(6), 7-16.

Hua, Z. (2010). Philosophy of learning. Global Education, 39(6), 13-17.

Inhelder, B., Sinclair, H., \& Bovet, M. (1974). Learning and the development of cognition (S. Wedgewood, trans.) Cambridge, MA: Harvard University Press.

Jianwei, Z. (2010). Intellectual Images and Teaching Models of Confucius and Socrates. Global Education, 39(6), 35.

Julien, J. (Ed.) (2005). Chaos, Complexity, Curriculum, and Culture: A Conversation. New York, NY: Peter Lang.

Keatinge, M.W. (1907). The great didactic of John Amos Comenius: translated into English and edited with biographical, historical and critical introductions. London, UK: Adam and Charles Black.

Levin, D.M. (1997). The listening self: Personal growth, social change and the closure of metaphysics (Z.M. Cheng, trans.) Shanxi, China: Shanxi People's Education Press.

Li, J. (2002). Listening: a way of presenting noumenon in Chinese philosophy. In Cheng, Zhongying (Ed.). Ontological hermeneutics II. Beijing, China: Beijing University Press.

Murray, D.M. (1979). The Listening Eye: Reflections on the Writing Conference. College English, $41(1), 13-18$.

Ong, W. (1983). Ramus, Method, and the Decay of Dialogue. Cambridge, MA: Harvard University Press;

Paulsen, F. (1976) German Education: Past and Present (T. Lorenz, trans.) London, UK: T. Fisher Unwin.

Piaget, J. (1990). A collection of Piaget's papers in education. (Lu Rui, trans.) Beijing, China: People's Education Press.

Qilong, L. (2002). Preface of the translator. In J.F. Herbart, General pedagogies and outlines of pedagogical lectures. (L. Qilong, trans.) Zhejiang Education Press.

Qiquan, Z. (2009). A critique on Kairov's pedagogy and a comment on the "Complex of Kairov's Pedagogy". Global Education, 38(1), 3-17.

Rousseau, J.-J. (1990). Emile. Excerpted from Piaget. A collection of Piaget's papers in education (Lu Rui ,trans.) Beijing, China: People's Education Press.

Smith, D. G. (2000). Globalization and postmodern pedagogy (G. Yangsheng, trans.) Beijing, China: Educational Sciences Press.

van Manen, M. (1990). Researching Lived Experience: Human science for an action sensitive pedagogy (2nd ed.) London, ON: The Althouse Press.

Wang, C. (1985). Lectures on teaching. Beijing, China: People's Education Press.

Wang, C. (2002). Teaching epistemology. Beijing, China: Normal University Press. 
Williams, R. (1961/2000). The Long Revolution. New York: Columbia University Press. In M.R. Himley \& P.F. Carini. Another angle: Children's Strengths and School Standards. New York, NY: Teachers College Press.

Xigui, Q. (2000). Chinese writing (G.L. Mattos \& J. Norman, trans.) New Haven, CT: Birdtrack Press.

Yang, D. (2007). Kairov's Pedagogy: an educational production of Stalin ideology. Global Education, 36(8), pp. 13-19.

Ying-shi, Y. (2004). Historical and literary traditions and cultural construction. Hong Kong, China: Joint Publishing.

\section{Acknowledgements}

I am grateful to Gao Zhenyu and $\mathrm{Yu}$ Jie for helping me translate this paper into English and make it readable. My thanks also go to Professor William E. Doll, Jr. for helping me improve this paper.

\section{About the Author}

Zhang Hua is Professor and Dean of Graduate School of Educational Science in Hangzhou Normal University in China and the president of International Association for the Advancement of Curriculum Studies (IAACS). He also serves National Educational Ministry in China, as the main expert for national curriculum reform. He is the editor of the journal Global Education and the journal of IAACS Transnational Curriculum Inquiry. As a Fulbright Scholar, he did research work at Harvard Graduate School of Education during 2002-2003 school year. His research interests include curriculum theory and pedagogy; Confucian perspective on curriculum; phenomenological and hermeneutic perspective on curriculum; curriculum reform; life-inquiry based curriculum; research-based classroom practice; philosophy of education; and moral education. He has published 9 books and more than 120 papers in academic journals.

(c) Copyright 2012. The author, Zhang Hua, assigns to the University of Alberta and other educational and non-profit institutions a non-exclusive license to use this document for personal use and in courses of instruction provided that the article is used in full and this copyright statement is reproduced. The authors also grant a non-exclusive license to the University of Alberta to publish this document in full on the World Wide Web, and for the document to be published on mirrors on the World Wide Web. Any other usage is prohibited without the express permission of the authors. 